\title{
$\alpha$-Tubulin Acetyltransferase Is a Novel Target Mediating Neurite Growth Inhibitory Effects of Chondroitin Sulfate Proteoglycans and Myelin- Associated Glycoprotein
}

\author{
Victor S. C. Wong, ${ }^{1}$ Cristina Picci, ${ }^{1,3}$ Michelle Swift, ${ }^{1}$ - Max Levinson, ${ }^{1}$ DDianna Willis, ${ }^{1,2}$ and Brett \\ Langley ${ }^{1,2,3}$
}

\section{DOI:http://dx.doi.org/10.1523/ENEURO.0240-17.2018}

${ }^{1}$ The Burke Medical Research Institute, White Plains, NY 10605, ${ }^{2}$ Brain and Mind Research Institute, Weill Cornell Medicine, New York, NY 10065, ${ }^{3}$ Health Sport and Human Performance, University of Waikato, Hamilton 3240, New Zealand

\section{Visual Abstract}

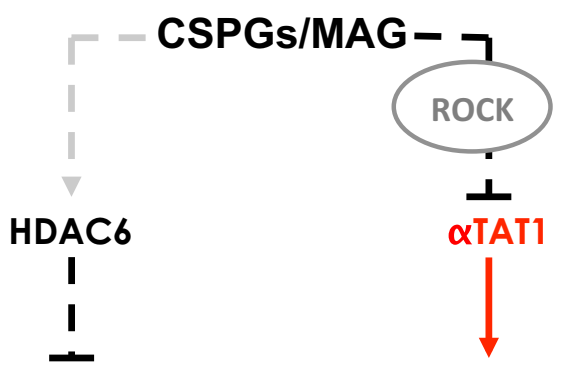

TUBULIN ACETYLATION

\section{AXONAL REGENERATION}

Damage to the CNS results in neuronal and axonal degeneration, and subsequent neurological dysfunction. Endogenous repair in the CNS is impeded by inhibitory chemical and physical barriers, such as chondroitin sulfate proteoglycans (CSPGs) and myelin-associated glycoprotein (MAG), which prevent axon regeneration. Previously, it has been demonstrated that the inhibition of axonal histone deacetylase-6 (HDAC6) can promote microtubule $\alpha$-tubulin acetylation and restore the growth of CSPGs- and MAG-inhibited axons. Since the acetylation of $\alpha$-tubulin is regulated by two opposing enzymes, HDAC6 (deacetylation) and $\alpha$-tubulin acetyltransferase-1 ( $\alpha$ TAT1; acetylation), we have investigated the regulation of these enzymes downstream of a growth inhibitory signal. Our findings show that exposure of primary mouse cortical neurons to soluble CSPGs and MAG substrates cause an acute and RhoA-kinase-dependent reduction in $\alpha$-tubulin acetylation and $\alpha$ TAT1 protein levels, without changes to either HDAC6 levels or HDAC6 activity. The CSPGs- and MAG-induced reduction in $\alpha$ TAT1 occurs primarily in the distal and middle regions of neurites and reconstitution of $\alpha \mathrm{TAT1}$, either by Rho-associated kinase (ROCK) inhibition or lentiviral-mediated $\alpha \mathrm{TAT} 1$ overexpression, can restore neurite growth. Lastly, we demonstrate that CSPGs and MAG signaling decreases $\alpha$ TAT1 levels posttranscriptionally via a ROCK-dependent increase in $\alpha \mathrm{TAT} 1$ protein turnover. Together, these findings define $\alpha$ TAT1 as a novel potential therapeutic target for ameliorating CNS injury characterized by growth inhibitory substrates that are prohibitive to axonal regeneration.

\section{Significance Statement}

Chondroitin sulfate proteoglycans (CSPGs) and myelin-associated glycoprotein (MAG) represent significant barriers to axon regeneration after CNS injury. Inhibition of axonal histone deacetylase-6 (HDAC6), an enzyme that regulates $\alpha$-tubulin deacetylation, has been shown to overcome the inhibitory effects of CSPGs and MAG to axon growth. In the present study, we report that $\alpha \mathrm{TAT1}$, the $\alpha$-tubulin acetyltransferase that opposes HDAC6's activity, is downregulated in neurites by CSPGs and MAG in cortical neurons in vitro. This reduction is associated with a loss of $\alpha$-tubulin acetylation and occurs via a RhoA-kinase-dependent pathway. Restoring $\alpha$ TAT1 expression in CSPGs- or MAG-inhibited cortical neurons rescues neurite growth. Our results suggest that $\alpha \mathrm{TAT} 1$ is a potential therapeutic target to promote axonal regeneration in the CNS. 
Key words: $\alpha$-tubulin acetylation; $\alpha$-tubulin acetyltransferase; chondroitin sulfate proteoglycan; myelinassociated glycoprotein

\section{Introduction}

CNS function requires the maintenance of axonal structural integrity and proper connectivity. As such, injury to axons often results in dysfunction, typified by the motor and sensory loss seen following spinal cord injuries. Exacerbating the consequences of injury, axonal regeneration in the CNS is limited, which results in the dysfunction becoming permanent (Dell'Anno and Strittmatter, 2017). Both intrinsic and extrinsic neuronal mechanisms contribute to failed axonal regeneration (Yiu and $\mathrm{He}, 2006$ ). Many extrinsic factors are a result of the injury environment and are regarded to be prohibitive to axon regrowth. These include, but are not limited to, chondroitin sulfate proteoglycans (CSPGs; McKeon et al., 1999; Jones et al., 2003; Tang et al., 2003), and myelin associated-glycoprotein (MAG; McKerracher et al., 1994; Mukhopadhyay et al., 1994). These factors induce signaling, via RhoA and Rhoassociated kinase (ROCK), which converges on the cytoskeletal network to inhibit axon growth (Dergham et al., 2002; Borisoff et al., 2003; Monnier et al., 2003; Mimura et al., 2006). Microtubules, which consist of cylindrical structures assembled from protofilaments of $\alpha$ - and $\beta$-tubulin heterodimers (Desai and Mitchison, 1997) and constitute a major component of the cellular and axonal cytoskeleton, play a critical role in axon extension and retraction. Microtubule lengths are variable, depending on the degree of assembly and disassembly at their plus and minus ends, making them highly dynamic. This dynamic structure is essential for many important cellular functions (Westermann and Weber, 2003), so it is not surprising that microtubules are under heavy and stringent regulation.

Posttranslational modification is a well-established mechanism of regulating microtubules dynamics, and this includes acetylation of $\alpha$-tubulin on lysine residue 40 (K40; Nogales et al., 1998; Janke and Bulinski, 2011). The importance of $\alpha$-tubulin K40 acetylation is underscored by several studies that reveal its role in promoting axonal transport, motor protein binding, and motility (Reed et al., 2006; Dompierre et al., 2007; Hammond et al., 2010; Alper et al., 2014; Godena et al., 2014). Using cell culture models, it has been shown that defective axonal transport can be rescued by $\alpha$-tubulin hyperacetylation (Dompierre

Received July 7, 2017; accepted January 18, 2018; First published February 15, 2018.

The authors declare no competing financial interests.

Author contributions: V.S.C.W. and B.L. designed research; V.S.C.W., C.P., M.S., and M.L. performed research; V.S.C.W. analyzed data; V.S.C.W., D.W., and B.L. wrote the paper.

This work was supported by the Miriam and Sheldon G. Adelson Medical Research Foundation and by the Burke Medical Research Foundation.

Correspondence should be addressed to Victor S. C. Wong, Burke Medical Research Institute, 785 Mamaroneck Avenue, White Plains, New York 10605, E-mail: viw3001@med.cornell.edu.

DOI:http://dx.doi.org/10.1523/ENEURO.0240-17.2018

Copyright (C) 2018 Wong et al.

This is an open-access article distributed under the terms of the Creative Commons Attribution 4.0 International license, which permits unrestricted use, distribution and reproduction in any medium provided that the original work is properly attributed. et al., 2007). Loss or reduction in $\alpha$-tubulin acetylation is associated with a number of neuropathological conditions, including familial dysautonomia, Alzheimer's disease, Huntington's disease, and Charcot-Marie-Tooth disease (Hempen and Brion, 1996; d'Ydewalle et al., 2001; Dompierre et al., 2007; Gardiner et al., 2007). Taken together, the injured axon requires numerous processes that are dependent on $\alpha$-tubulin acetylation to initiate regrowth.

Previous studies have shown that $\alpha$-tubulin K40 deacetylation is a primary and non-nuclear function of the class II zinc-dependent histone deacetylase (HDAC) family member, HDAC6 (Zhang et al., 2003; Zhang et al., 2008). By contrast, MEC-17/ $\alpha$-tubulin acetyltransferase- 1 ( $\alpha$ TAT1) is the enzyme responsible for $\alpha$-tubulin K40 acetylation (Akella et al., 2010; Shida et al., 2010). Several studies to date have suggested important roles for HDAC6 and $\alpha$ TAT1 in regulating $\alpha$-tubulin K40 acetylation and neurite outgrowth. In cultured neurons, pharmacological inhibition or knockdown of HDAC6 can prevent the inhibitory actions of MAG and CSPGs on axonal growth (Rivieccio et al., 2009). Similarly, it has been shown that $\alpha$ TAT1 is required for mechanosensation in Caenorhabditis elegans and that loss of $\alpha \mathrm{TAT} 1$ leads to disruption of microtubule structural integrity and axonal morphologic defects in touch receptor neurons (Cueva et al., 2012; Topalidou et al., 2012). Moreover, the loss of $\alpha$ TAT1 disrupts axonal transport, leading to spontaneous axonal degeneration (Neumann and Hilliard, 2014). Studies in more complex organisms such as zebrafish and mice have shown that the loss of $\alpha$ TAT1 results in neuromuscular defects (Akella et al., 2010) and brain abnormalities, respectively (Kim et al., 2013).

Here, we demonstrate that $\alpha$ TAT1 plays an important role in the acetylation of $\alpha$-tubulin required for axon growth. We show that in the presence of MAG or CSPGs, $\alpha$ TAT1 levels are reduced, resulting in decreased axonal $\alpha$-tubulin K40 acetylation. This reduction in $\alpha$ TAT1 level is mediated via RhoA-ROCK signaling, is a result of decreased $\alpha$ TAT1 protein stability, and that reconstitution of $\alpha$ TAT1 by ROCK inhibition or lentiviral-mediated $\alpha$ TAT1 expression is sufficient to restore growth to MAG- and CSPGs-inhibited axons. In contrast to $\alpha \mathrm{TAT} 1$, under these conditions HDAC6 levels and activity are unchanged following MAG and CSPGs exposure. Based on our data, we suggest a model of axon growth control through $\alpha$-tubulin acetylation via the competing acetyltransferase and deacetylase activities of $\alpha$ TAT1 and HDAC6, respectively.

\section{Materials and Methods}

\section{Antibodies and reagents}

The following antibodies were used: CSPGs $(2 \mu \mathrm{g} / \mathrm{ml}$; CC117, EMD Millipore), cycloheximide $(10 \mu \mathrm{g} / \mathrm{ml}$; C0934, Sigma Aldrich), recombinant rat myelin-associated glycoprotein (MAG; $30 \mu \mathrm{g} / \mathrm{ml}$; P07722, R\&D Systems), Y-27632 ROCK inhibitor (10 $\mu \mathrm{M}$; 1254, Tocris Bioscience), anti$\alpha \operatorname{TAT} 1$ (1:200; ab58742, Abcam), anti-HDAC6 (1:500; NB100-91805, Novus Biologicals), anti-acetylated $\alpha$-tubulin 
(1:1000; D20G3, Cell Signaling Technology), anti- $\alpha$-tubulin (1:5000; DM1A, Sigma-Aldrich), anti- $\beta$-actin (1:5000; AC-74, Sigma-Aldrich), anti- $\beta$ III tubulin (1:5000; $\mathrm{MRB}_{435} \mathrm{P}$, BioLegend) and anti-GFP (1:500; Sigma-Aldrich). Lentivirus containing GFP (control) or GFP-tagged wild-type $\alpha T A T 1$ constructs, under the human cytomegalovirus (CMV) promoter, was purchased from Dr. Mingije Li (Washington University School of Medicine, St. Louis, MO; Li et al., 2010). HDAC6 activity was determined using the fluorometric HDAC6 Activity Assay kit (BioVision), as per manufacturer's instructions.

\section{Primary neurons}

Fetuses of embryonic day 15.5 were obtained from timed pregnant female CD1 mice (Charles River). All animal procedures were performed in accordance with the Burke Medical Research Institute and Weill Cornell Medicine animal care committee's regulations. Mouse primary neuronal cultures were obtained as described (Rivieccio et al., 2009). Briefly, neurons were allowed to adhere overnight before treatment at indicated concentration and duration (i.e., 30 $\min$ and $2 \mathrm{~h}$ ). Lentiviral transduction conditions were optimized and were performed on neo-cortical cultures $2 \mathrm{~d}$ after plating (DIV 2) for $4 \mathrm{~h}$ of incubation, with no media change. Cultures were transduced with concentrated viruses at a multiplicity of infection of 5. Media were then replaced, and neurons were treated with CSPGs or MAG the next day for $24 \mathrm{~h}$.

\section{Immunoblotting and immunocytochemistry}

Protein lysates were prepared from cell cultures using RIPA buffer (Boston Bioproducts). Briefly, cells were grown in coated plates and rinsed with ice-cold PBS and centrifuged for $10 \mathrm{~min}$ at $\geq 16,000 \times \mathrm{g}$. Pellet was collected and resuspended in RIPA buffer, and then further centrifuged for an additional $5 \mathrm{~min}$ at $\geq 16,000 \times \mathrm{g}$. Protein concentration was determined by DC protein assay (5000112; Bio Rad). Immunoblot analysis was performed using a Li-Cor Odyssey system as described by Langley et al. (2008). For immunocytochemistry, primary cortical neurons were plated on poly-D-lysine (P6407; SigmaAldrich) wells and were fixed with $4 \%$ paraformaldehyde (BM-155-5; Boston BioProducts) for 10 min. Primary antibodies were used in conjunction with Alexa Fluor 488- or 594-conjugated secondary antibodies (1:2000; Invitrogen) for detection. Slides were mounted with ProLong antifade Gold reagent with DAPI (1:5000; Invitrogen). Immunostaining was examined under Carl Zeiss LSM 510 META confocal microscope for conventional single plane image. Image analyses were performed in Zen software (Carl Zeiss). All images were matched for exposure, gain, excitation power, and postprocessing. Localization analyses were performed using line scan profiling, and lines were drawn using ImageJ's "line" tool that enable to measure peak intensity through the region of interest. To maintain consistency, neurite initiating segment (NIS) and distal region were measured $0.5 \mu \mathrm{m}$ from the hillock and furthest end of the neurite (specified by Tuj 1 positivity), respectively. The middle segment of the neurite was located to be half the length of the neurite. Intensities of acetylated $\alpha$-tubulin and $\alpha$ TAT1 were normalized to total tubulin and Tuj1, respectively. For neurite length measure- ments, one longest neurite per neuron were measured from the cell body to end of the process labeled positively with Tuj1. For lentivirus overexpression experiments, only the neurites from GFP-positive neurons were measured.

\section{Real-time PCR}

Total RNA preparation from cultured cells was performed as described in (Langley et al., 2008). TaqMan RNA-to-Ct one-step (4392938; Invitrogen) real-time PCRs were performed on total RNA as a duplex reaction using aTAT1 gene expression assay (Mm00551286_m1; Applied Biosystems), and a VIC-labeled $\beta$-actin gene expression assay (4352341E; Applied Biosystems).

\section{Statistics}

One- or two-way ANOVA, followed by the Bonferroni's post hoc tests, or Student's $t$ tests were used to measure statistical significance; $p<0.05$ was considered to be statistically significant.

\section{Results}

\section{$\alpha$ TAT1 is downregulated by the axon growth inhibitory factors, CSPGs, and MAG}

CSPGs and MAG are well-characterized molecular barriers to axon regeneration following CNS injury. In the present study, we examined whether neuronal exposure to either CSPGs or MAG results in a change in $\alpha$-tubulin acetylation levels. Cultured primary cortical neurons were treated with soluble CSPGs $(2 \mu \mathrm{g} / \mathrm{ml})$ or MAG $(30 \mu \mathrm{g} / \mathrm{ml})$ for $30 \mathrm{~min}$ or $2 \mathrm{~h}$, harvested, and lysates assessed for $\alpha$-tubulin acetylation by immunoblot analysis. Our results showed a significant decrease of $\alpha$-tubulin acetylation within 30 min of exposure to MAG and within $2 \mathrm{~h}$ of exposure to CSPGs (Fig. 1A,B). Since $\alpha$-tubulin acetylation level is determined by $\alpha$-tubulin deacetylase and acetyltransferase activity, we examined HDAC6 and $\alpha$ TAT1 levels under these conditions. Immunoblot analysis for HDAC6 in lysates from CSPGs- or MAG-treated neurons showed no change in HDAC6 protein level (Fig. $1 C, D)$. To determine whether HDAC6 activity, rather than level, contributed to the $\alpha$-tubulin acetylation change by CSPGs and MAG, we examined HDAC6 enzymatic activity using fluorometric HDAC6 activity assay. No change in HDAC6 activity was observed in lysates from neurons exposed to either CSPGs or MAG (Fig. 1E,F). We then examined whether changes in $\alpha$-tubulin acetylation were associated with changes in $\alpha$ TAT1 protein. Treatment with CSPGs or MAG significantly downregulated $\alpha$ TAT1 protein levels (Fig. 1G,H), and their effects were similar to the changes in $\alpha$-tubulin acetylation with respect to time and magnitude (Fig. 1A,B). Taken together, these results indicate that the acute decrease in acetylation levels of $\alpha$-tubulin in response to growth inhibitory factors is independent of HDAC6 levels and activity and can be attributed to a decrease in $\alpha \mathrm{TAT} 1$ protein levels.

\section{Regulation of $\alpha$ TAT1 protein levels by CSPGs or MAG is ROCK dependent}

It is well established that MAG and CSPGs exert growth inhibitory effects via distinct receptors. For instance, MAG has been shown to activate the small GTPase RhoA via 
A

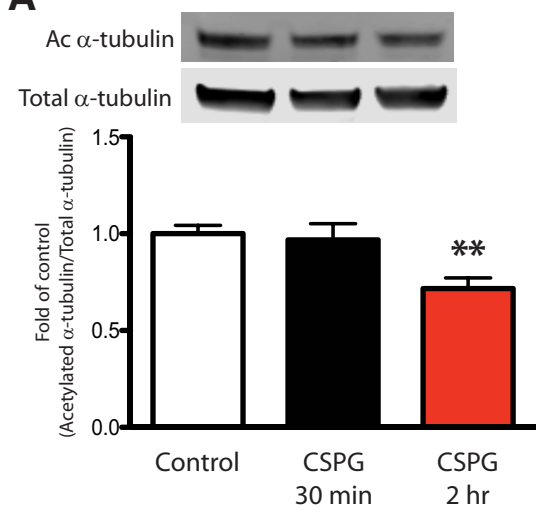

C
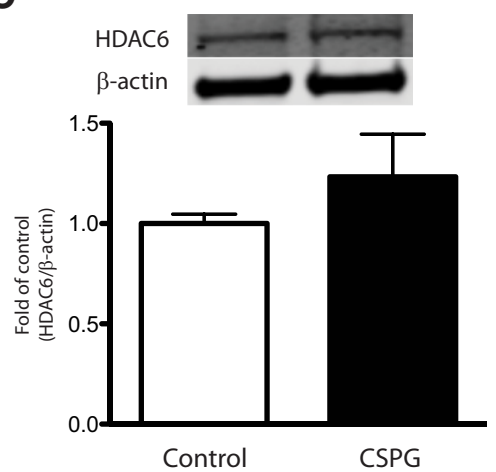

E

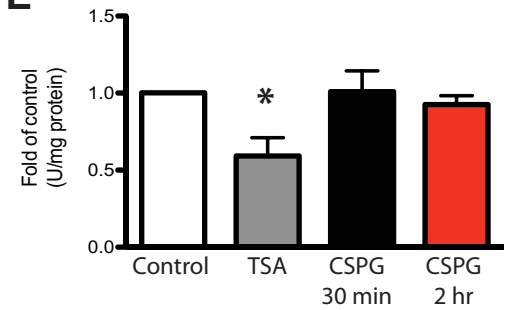

G

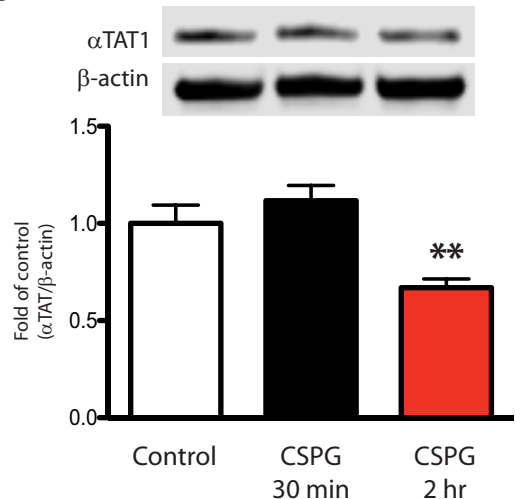

B

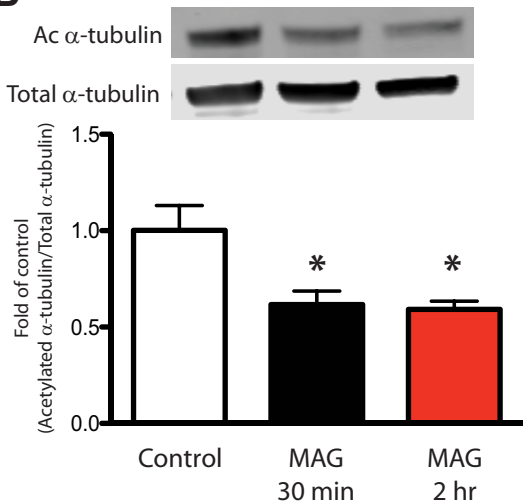

D
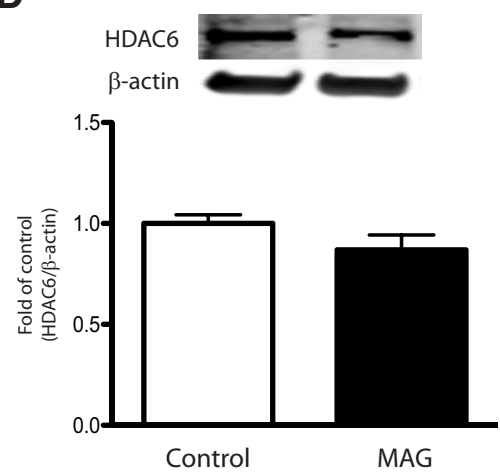

F

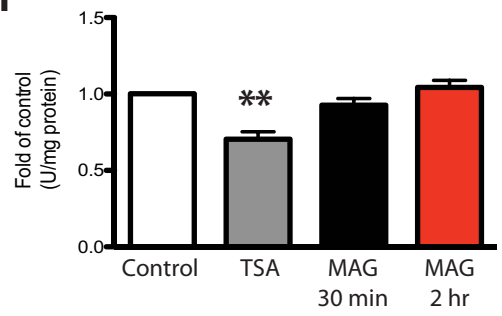

H

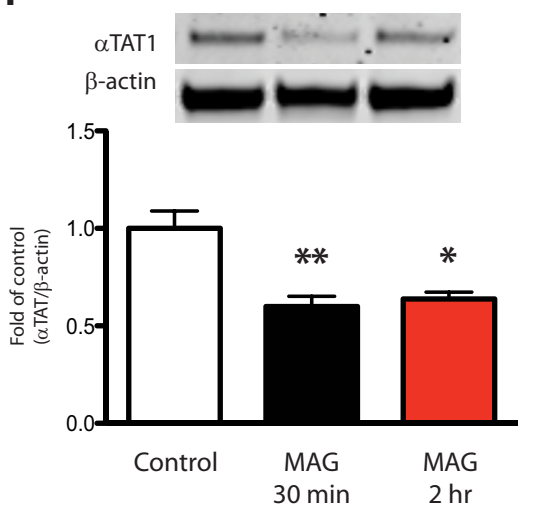

Figure 1. Growth inhibitory factors downregulate $\alpha$-tubulin acetylation and $\alpha$ TAT1 levels. $\boldsymbol{A}, \boldsymbol{B}$, Immunoblot analysis of primary murine cortical neurons after exposure to soluble CSPGs $(2 \mu \mathrm{g} / \mathrm{ml} ; \boldsymbol{A})$ or MAG $(30 \mu \mathrm{g} / \mathrm{ml} ; \boldsymbol{B})$ showed a significant decrease in $\alpha$-tubulin acetylation levels at the indicated times. Acetylated $\alpha$-tubulin was normalized to total $\alpha$-tubulin from the same immunoblot. $\boldsymbol{C}, \boldsymbol{D}$, Immunoblot analysis for HDAC6 after incubation with CSPGs $(\boldsymbol{C})$ or MAG (D) for $2 \mathrm{~h}$. HDAC6 level was normalized to $\beta$-actin from the same immunoblot. $\boldsymbol{E}, \boldsymbol{F}$, HDAC6 activity assays in primary neurons exposed to CSPGs $(\boldsymbol{E})$ or MAG $(\boldsymbol{F})$ after 30 min or $2 \mathrm{~h}$ did not change HDAC6 activity. Tubastatin A, a specific HDAC6 inhibitor, was used a positive control. $\boldsymbol{G}, \boldsymbol{H}$, Immunoblot analysis for $\alpha$ TAT1 after incubation with CSPGs $(\boldsymbol{G})$ or MAG $(\boldsymbol{H})$ for $30 \mathrm{~min}$ or $2 \mathrm{~h}$ showed a signification reduction in $\alpha$ TAT1 protein levels. $\alpha$ TAT1 level was normalized to $\beta$-actin from the same immunoblot. $*$, Significant downregulation compared to the control group $p<0.05 ; * * p<$ 0.01 (one-way ANOVA followed by Bonferroni's post hoc test was performed for $\boldsymbol{A}, \boldsymbol{B}, \boldsymbol{E}-\boldsymbol{H}$. Student's $t$ test was performed for $\boldsymbol{C}, \boldsymbol{D}$ ). 
A

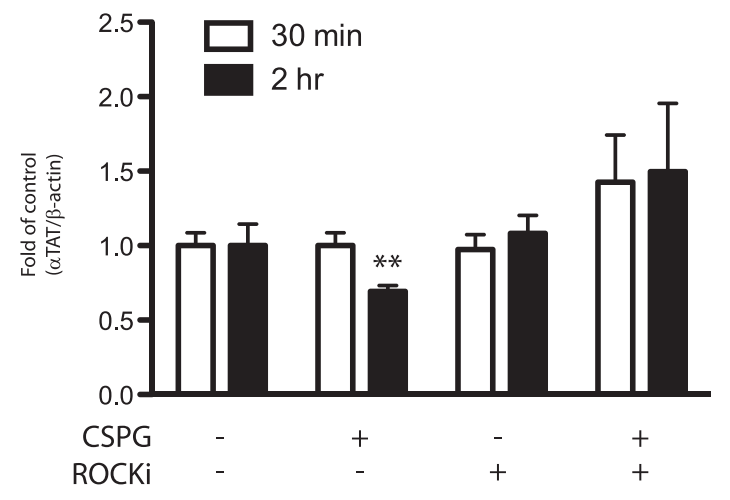

C

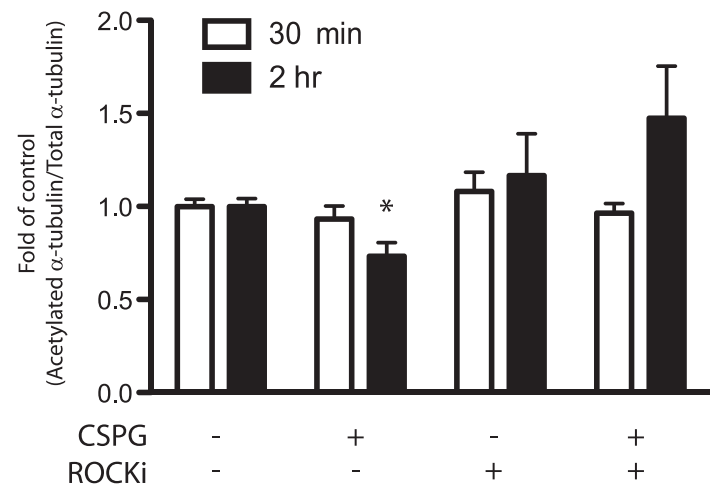

B

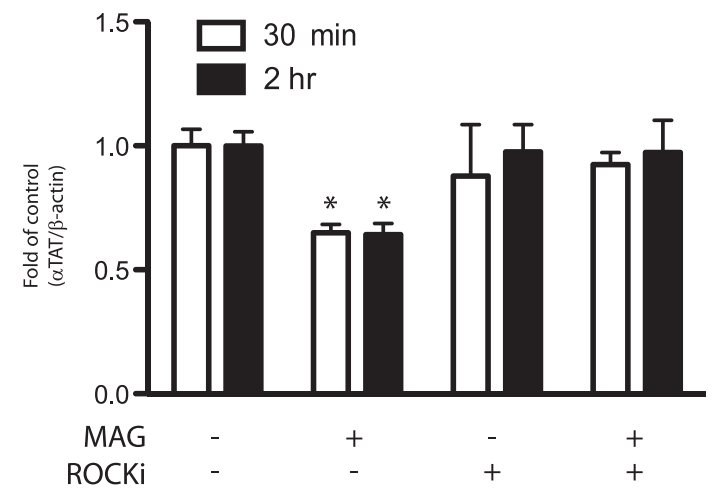

D

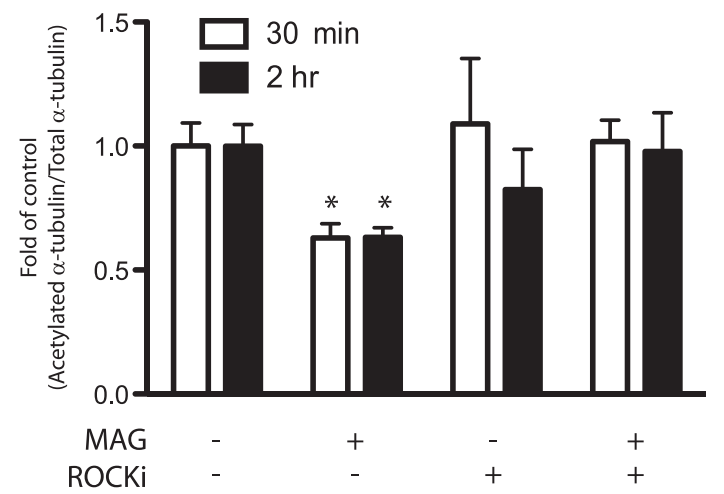

Figure 2. Downregulation of $\alpha \mathrm{TAT} 1$ and $\alpha$-tubulin acetylation by CSPGs and MAG is mediated through ROCK-dependent pathway. Primary cortical neurons were treated with either CSPGs $(2 \mu \mathrm{g} / \mathrm{ml})$ or MAG $(30 \mu \mathrm{g} / \mathrm{ml})$ at indicated times, with or without ROCK inhibitor (Y-27632; $10 \mu \mathrm{M})$. A, B, Immunoblot analysis for $\alpha$ TAT1 showed that ROCK inhibitor prevented downregulation of $\alpha$ TAT1 after exposure to CSPGs $(\boldsymbol{A})$ and MAG $(\boldsymbol{B})$. $\alpha$ TAT1 level was normalized to $\beta$-actin from the same immunoblot. $\boldsymbol{C}, \boldsymbol{D}$, Immunoblot analysis for acetylated $\alpha$-tubulin showed that ROCK inhibitor also prevented CSPGs- and MAG-induced (C, $\boldsymbol{D}$, respectively) reduction of $\alpha$-tubulin acetylation. Acetylated $\alpha$-tubulin was normalized to total $\alpha$-tubulin from the same immunoblot. *, Significant downregulation compared to the control group at their respective times, $p<0.05 ; * * p<0.01$ (two-way ANOVA followed by Bonferroni's post hoc test was performed).

NogoR (Fournier et al., 2001; Domeniconi et al., 2002; Liu et al., 2002; Wang et al., 2002b) and p75 neurotrophin (Wang et al., 2002a; Wong et al., 2002; Yamashita et al., 2002) receptors, leading to subsequent activation of RhoA and its downstream kinase, ROCK (Dergham et al., 2002; Yamashita et al., 2002; Fournier et al., 2003). Although CSPGs use PTP $\sigma$ to activate yet unidentified pathways (Shen et al., 2009), studies have shown that the RhoA/ROCK pathway also mediates the neurite growth-inhibitory activity of CSPGs (Dergham et al., 2002; Borisoff et al., 2003; Monnier et al., 2003). Since the inhibitory signals of CSPGs and MAG may converge on the RhoA/ROCK pathway, we next delineated the mechanism of action whereby CSPGs or MAG regulates $\alpha$ TAT1. Primary cortical neurons were cotreated with CSPGs or MAG, and Y-27632, a well-established ROCK inhibitor. Consistent with our prior observations (Fig. 1A,B), CSPGs and MAG reduced $\alpha$ TAT1 protein levels (Fig. $2 A, B$ ). Cotreatment with the ROCK inhibitor prevented this effect (Fig. 2A,B). Furthermore, the reduction in $\alpha$-tubulin acetylation was prevented when both the ROCK inhibitor and either growth inhibitory substrates were applied (Fig. 2C,D). In line with our observations in Figure 1C,D, no changes in HDAC6 protein levels were seen under these conditions (data not shown).
These findings indicate that $\alpha \mathrm{TAT} 1$ regulation by CSPGs and MAG is ROCK dependent.

\section{$\alpha$ TAT1 downregulation by CSPGs and MAG predominantly occurs in the middle and distal regions of neurites}

In addition to measuring global changes of $\alpha$ TAT1 levels in cortical neurons via immunoblotting, we further examined the effects of CSPGs and MAG on $\alpha$ TAT1 levels in different regions of neurites. Primary cortical neurons were cultured for $24 \mathrm{~h}$, treated with soluble CSPGs or MAG for 30 min or $2 \mathrm{~h}$, and immunostained for $\alpha \mathrm{TAT} 1$. Our immunostaining results indicated that in control neurons, $\alpha$ TAT1 was evenly distributed from the cell body to the distal end of the neurite. Consistent with previous studies (Shida et al., 2010), $\alpha$ TAT1 was not localized to the nucleus of cortical neurons. By contrast, a 2-h exposure to CSPGs resulted in a significant reduction in $\alpha$ TAT1 intensity in the middle and distal regions of neurites (Fig. $3 A-C$ ). Similarly, exposure to MAG resulted in significant reduction in the middle and distal regions of the neurite; however, this reduction occurred within $30 \mathrm{~min}$ and was also seen in the proximal (NIS) region of the neurite (Fig. 3D-F). Administration of 
A

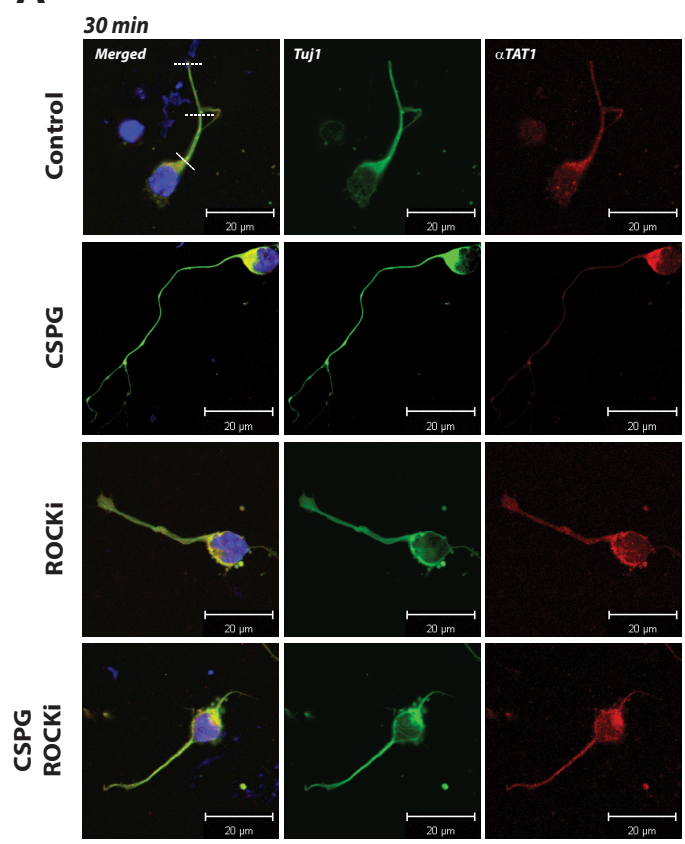

D
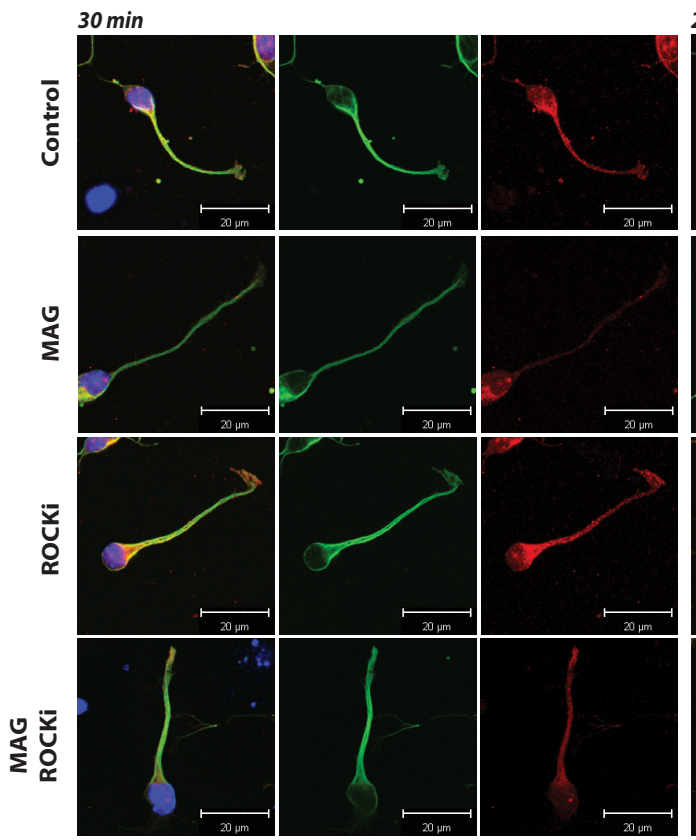
$2 \mathrm{hr}$
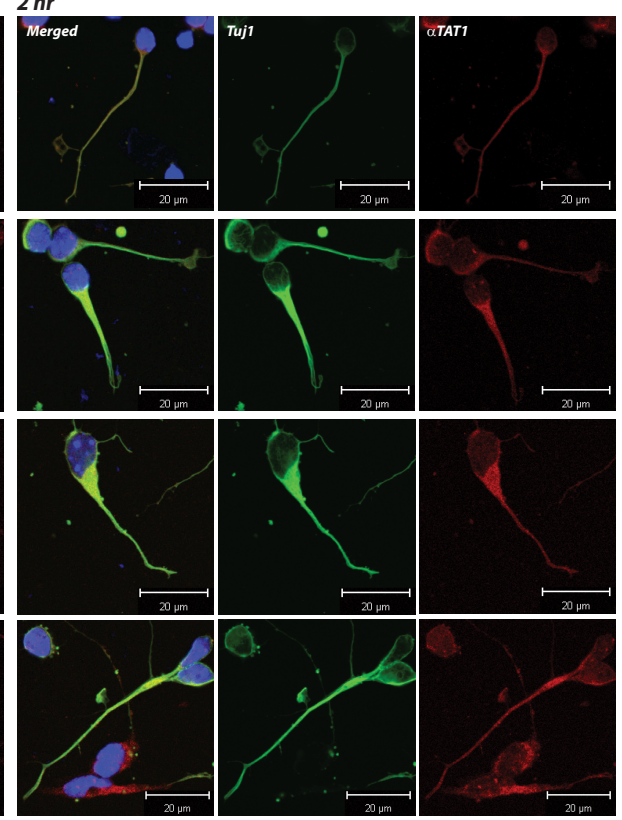

$2 \mathrm{hr}$
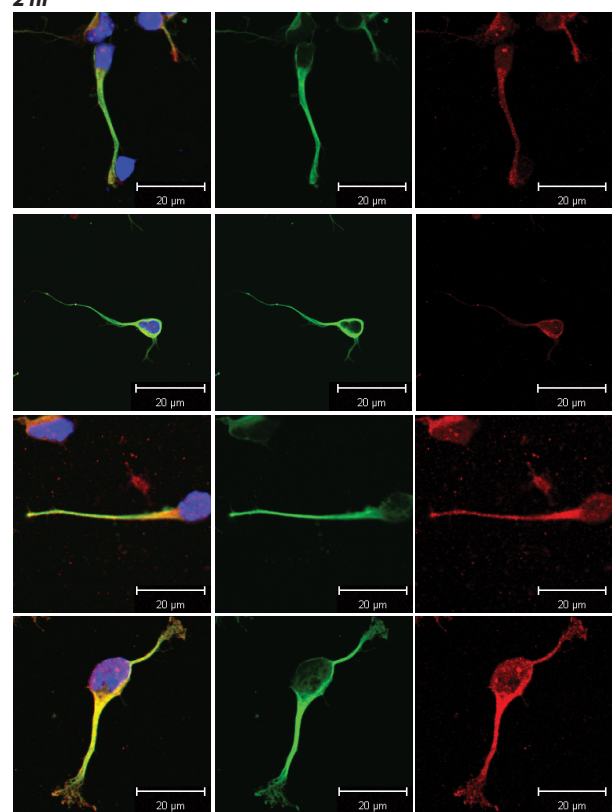

B

$\square$ Distal

$\square$ Middle

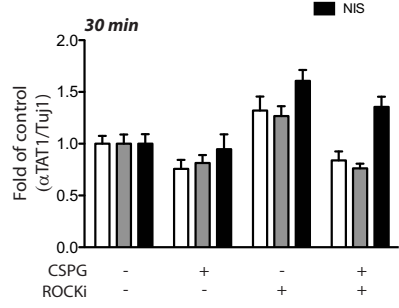

C

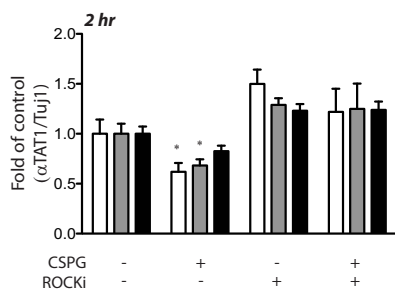

E

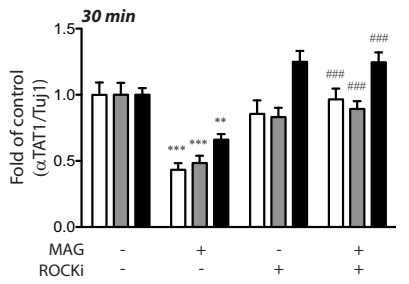

F

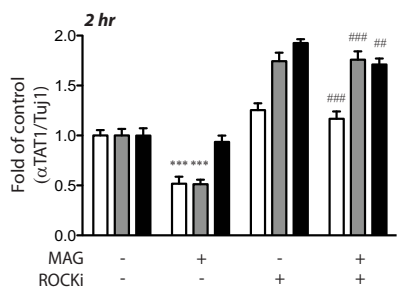

Figure 3. CSPGs and MAG change neurite $\alpha \mathrm{TAT} 1$ expression. $\boldsymbol{A}, \boldsymbol{D}$, Confocal immunofluorescent micrographs showing the distribution of $\alpha$ TAT1 in cortical neurons after exposure to growth inhibitory factors CSPGs $(2 \mu \mathrm{g} / \mathrm{ml} ; \boldsymbol{A})$ or $\mathrm{MAG}(30 \mu \mathrm{g} / \mathrm{ml} ; \boldsymbol{D})$ with or without ROCK inhibitor (Y-27632; $10 \mu \mathrm{M})$ after 30 min and $2 \mathrm{~h}$. Immunolabeling was performed using antibodies against $\alpha$ TAT1 (1:200; red) and Tuj1 (1:5000; green). Nuclei of neurons were labeled with DAPI (blue). Immunofluorescence intensity at different regions of the axon as indicated by white dashed line (i.e., distal, middle, and NIS) was quantified in $\boldsymbol{B}, \boldsymbol{C}$ and $\boldsymbol{E}, \boldsymbol{F}$. $*$, Treatment versus control $p<0.05$; **, treatment versus control $p<0.01 ; * * *$, treatment versus control $p<0.001$; \#\#, cotreatment with MAG and ROCKi versus MAG alone $p<0.01$; \#\#\#, cotreatment with MAG and ROCKi versus MAG alone $p<0.001$ (two-way ANOVA followed by Bonferroni's post hoc test was performed). Scale bar, $20 \mu \mathrm{m}$.

the ROCK inhibitor, Y-27632, alone did not significantly alter $\alpha$ TAT1 localization compared with control neurons, but when co-administered with CSPGs or MAG it prevented the $\alpha$ TAT1 reduction in the neurites. Immunostaining using an antibody against acetylated $\alpha$-tubulin revealed a similar pattern of $\alpha$-tubulin acetylation change to that observed for $\alpha$ TAT1. Significant decreases in acetylated $\alpha$-tubulin were predominantly seen in distal to middle regions with CSPGs (Fig. $4 A-C$ ) or MAG (Fig. $4 D-F)$ treatment. The distal neurite $\alpha$-tubulin acetylation 
A

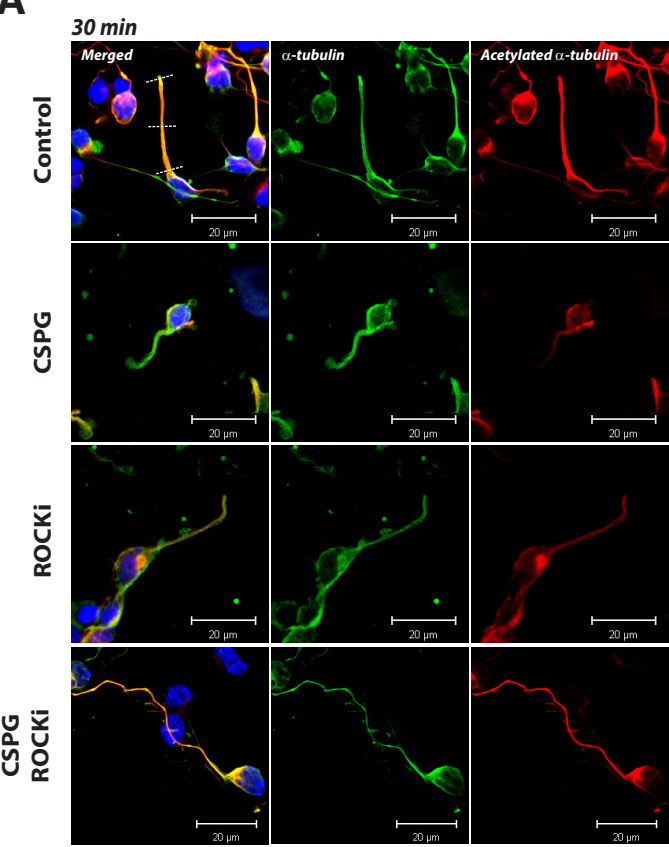

D
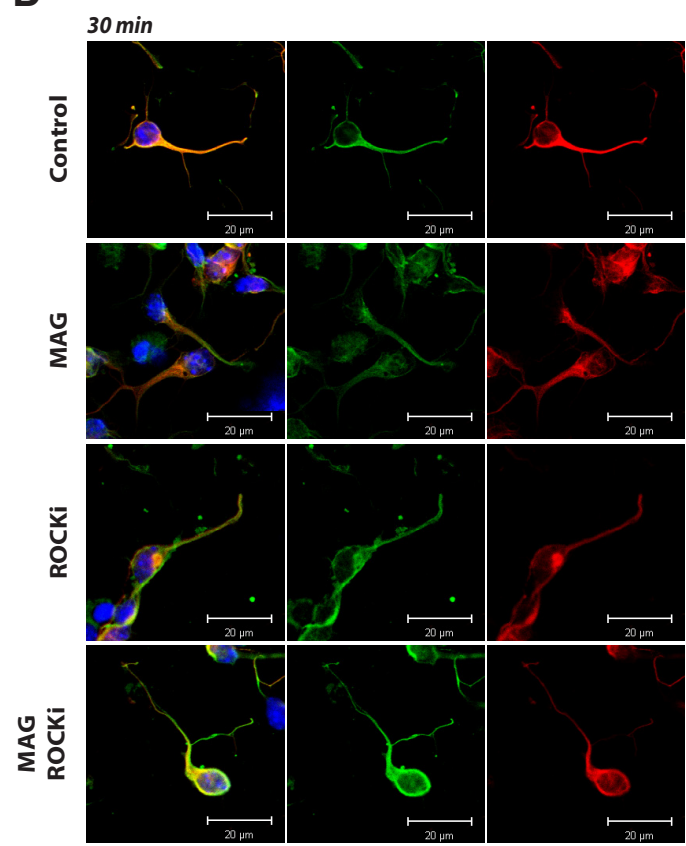

$2 \mathrm{hr}$

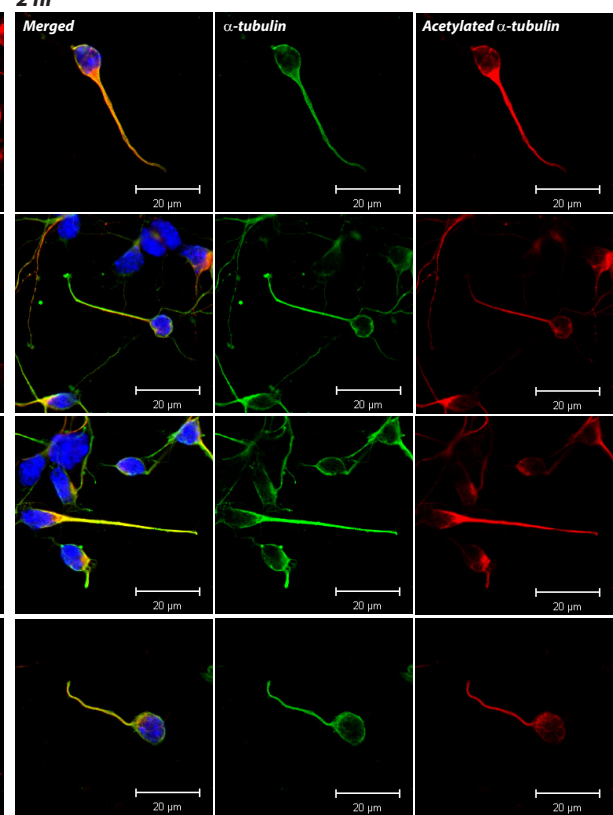

$2 \mathrm{hr}$
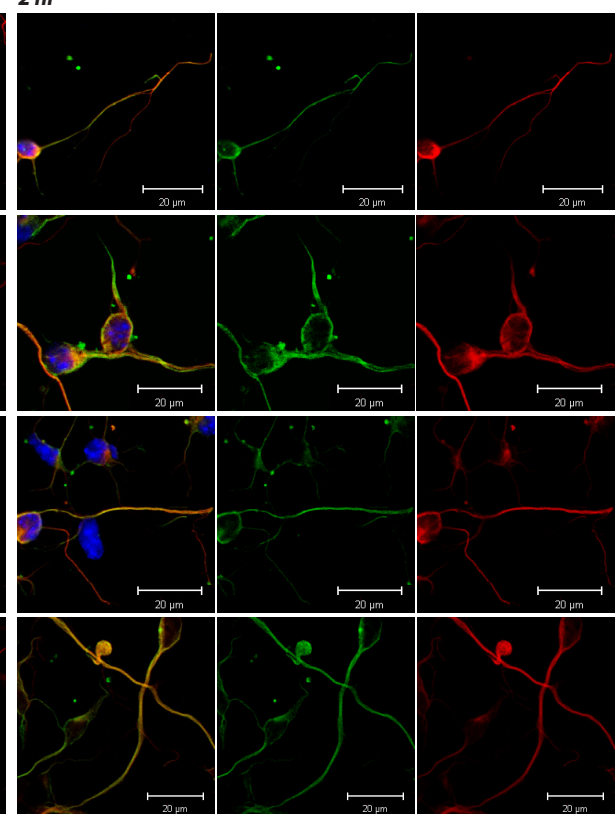

B

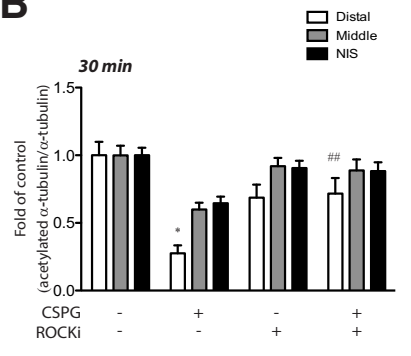

C

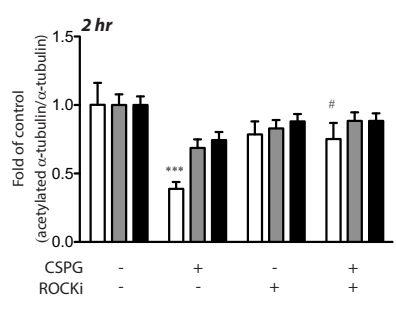

E

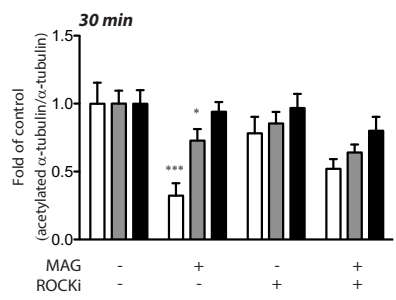

F

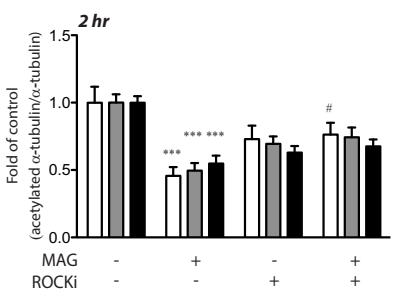

Figure 4. CSPGs and MAG change neurite $\alpha$-tubulin acetylation. $\boldsymbol{A}, \boldsymbol{D}$, Confocal immunofluorescent micrographs showing the distribution of $\alpha$ TAT1 in cortical neurons after exposure to growth inhibitory factors CSPGs $(2 \mu \mathrm{g} / \mathrm{ml} ; \boldsymbol{A})$ or MAG $(30 \mu \mathrm{g} / \mathrm{ml} ; \boldsymbol{D})$ with or without ROCK inhibitor (Y-27632; $10 \mu \mathrm{M})$ after $30 \mathrm{~min}$ and $2 \mathrm{~h}$. Immunolabeling was performed using antibodies against acetylated $\alpha$-tubulin (1:1000; red) and $\alpha$-tubulin (1:5000; green). Nuclei of neurons were labeled with DAPI (blue). Immunofluorescence intensity at different regions of the axon as indicated by white dashed line (i.e., distal, middle, and NIS) was quantified in $\boldsymbol{B}, \boldsymbol{C}$ and $\boldsymbol{E}, \boldsymbol{F}$. *, Treatment versus control $p<0.05$; ***, treatment versus control $p<0.001$; \#, cotreatment with ROCKi versus treatment alone $p<0.05$; \#\#, cotreatment with ROCKi versus treatment alone $p<0.01$ (two-way ANOVA followed by Bonferroni's post hoc test was performed). Scale bar, $20 \mu \mathrm{m}$.

decrease by CSPGs was attenuated by cotreatment with the ROCK inhibitor at 30 min and $2 \mathrm{~h}$, while the decrease by MAG was attenuated by cotreatment with the ROCK inhibitor at $2 \mathrm{~h}$ (Fig. 4). Attenuation of $\alpha$-tubulin acetylation decrease by MAG at $30 \mathrm{~min}$ did not reach a level of significance (Fig. 4E).

\section{$\alpha$ TAT1 downregulation by CSPGs and MAG}

\section{correlates with decreased neurite length}

Based on our observations that CSPGs and MAG decrease $\alpha$ TAT1 expression and $\alpha$-tubulin acetylation, we hypothesized that $\alpha$ TAT1 decrease is responsible for the inhibition of neurite outgrowth. To test this hypothesis, we 
examined the effects of CSPGs and MAG on neurite length in the presence or absence of ROCK inhibitor. Cultured primary cortical neurons were plated, cultured for $4 \mathrm{~h}$, then treated with soluble CSPGs $(2 \mu \mathrm{g} / \mathrm{ml})$ or MAG (30 $\mu \mathrm{g} / \mathrm{ml})$ in the presence of the ROCK inhibitor, Y-27632, for 24 h. Consistent with our previous findings (Rivieccio et al., 2009), and our current findings that CSPGs and MAG decrease $\alpha$ TAT1 and $\alpha$-tubulin acetylation levels, treatment with either CSPGs (Fig. $5 A$ ) or MAG (Fig. 5B) significantly reduced neurite length in cortical neurons ( $42 \%$ and $25 \%$ reduction, respectively). Cotreatment with ROCKi restored neurite growth (44\% compared to CSPGs treatment alone; $66 \%$ compared to MAG treatment alone) indicating that the axon growth inhibitory effect of either CSPGs (Fig. 5A) or MAG (Fig. 5B) was dependent on ROCK. To demonstrate a causative relationship for reduced $\alpha$ TAT1 and inhibited neurite growth, we reconstituted $\alpha$ TAT1 expression to CSPGs- or MAGtreated neurites. Primary cortical neurons (DIV 2) were infected with $\alpha T A T 1$-GFP-lentivirus or GFP-lentivirus (control) for $4 \mathrm{~h}$. Media were then replaced, and neurons were treated with CSPGs or MAG for $24 \mathrm{~h}$. Assessments of neurite length from infected (GFP-positive) cortical neurons show that $\alpha T A T 1$-lentivirus-mediated overexpression of $\alpha$ TAT1 significantly reversed the growth inhibitory effects of CSPGs and MAG (Fig. 5C,D, respectively; $80 \%$ compared CSPGs treatment alone, and $169 \%$ relative to MAG treatment alone).

\section{CSPGs- and MAG-induced $\alpha$ TAT1 decrease occurs via a change in $\alpha$ TAT1 protein stability}

The observed downregulation of $\alpha$ TAT1 in neurites treated with CSPGs or MAG could occur via changes in $\alpha T A T 1$ transcription or $\alpha$ TAT1 protein stability. To determine whether transcription of $\alpha T A T 1$ is decreased with CSPGs or MAG treatment, primary cortical neurons were treated with CSPGs or MAG for 30 min or $2 \mathrm{~h}$, harvested and analyzed for $\alpha T A T 1$ expression by quantitative RTPCR. No significant changes in $\alpha T A T 1$ mRNA levels were observed in any of the conditions (Fig. $6 A, B$ ), suggesting that the reduction in $\alpha \mathrm{TAT} 1$ protein levels in response to growth inhibitory factors is dependent on $\alpha T A T 1$ transcription. To determine whether the changes $\alpha \mathrm{TAT} 1$ reflect in a change in protein stability, we performed cycloheximide chase assays in CSPGs or MAG-treated primary neurons. In cycloheximide-treated $(10 \mu \mathrm{g} / \mathrm{ml})$ control neurons, the levels of $\alpha \mathrm{TAT} 1$ protein remained relatively steady over the 2-h course of the experiment (Fig. 6C,D). By contrast, we saw a significant reduction in $\alpha$ TAT1 protein levels within 30 min with CSPGs (Fig. $6 C$ ) or MAG (Fig. 6D), which persisted at the 2-h time point. Similar to controls, the cotreatment of neurons with cycloheximide and the ROCK inhibitor, Y-27632, resulted in no significant changes in $\alpha$ TAT1 levels during the 2-h course of the experiment; however, cotreatment with Y-27632 could prevent $\alpha$ TAT1 protein decrease observed by CSPGs (Fig. 6C) or MAG treatment alone (Fig. 6D). These observations strongly suggest that the reduction in $\alpha \mathrm{TAT} 1$ seen with MAG or CSPGs treatment is due to a
ROCK-dependent increase in the turnover rate of this protein.

\section{Discussion}

Previous studies have established that CSPGs and MAG play critical roles in the extrinsic inhibition of axon regeneration following CNS injury. Thus, they have been widely studied, both in vitro and in vivo, to identify of molecular targets that can be manipulated to overcome CNS regeneration failure, with the ultimate goal of reducing dysfunction and disability. Previous studies have highlighted the role of HDAC6 in mediating the growth inhibitory effects of MAG and CSPGs. Moreover, these studies identified HDAC6 as a novel target for pharmacological inhibition or genetic downregulation using small molecule inhibitors or siRNAs, respectively, which can promote neurite outgrowth in multiple models of growth inhibition using MAG and CSPGs (Rivieccio et al., 2009).

In this study, we show that the microtubule protein, $\alpha$-tubulin, which is one of the most recognized intracellular protein targets of HDAC6, is deacetylated in neurons following stimulation by CSPGs or MAG (Fig. $1 A, B$ ). This deacetylation was most striking in the distal portion of neurites, but also occurred in the middle and proximal regions (Fig. 3A-F). Given that HDAC6 inhibition can rescue neurite outgrowth in CSPGs- or MAG-stimulated neurons and can increase $\alpha$-tubulin acetylation (Rivieccio et al., 2009), we thought it logical that CSPGs or MAG might regulate $\alpha$-tubulin acetylation via HDAC6; however, under these conditions, we saw no evidence for altered HDAC6 levels or its enzymatic activity downstream of CSPGs or MAG signaling (Fig. 1C-F). By contrast, under the same growth inhibitory conditions, our findings reveal that $\alpha$ TAT1 levels were significantly downregulated (Fig. $1 G, H)$. Since $\alpha$-tubulin acetylation is regulated by the opposing activities of HDAC6 (deacetylase) and $\alpha$ TAT1 (acetyltransferase), our results suggest that $\alpha \mathrm{TAT} 1$ regulation is the main driver of CSPGs- or MAG-induced $\alpha$-tubulin acetylation loss in the neurite. This notion is highly supported by our findings that $\alpha \mathrm{TAT} 1$ downregulation is both temporally and spatially identical to $\alpha$-tubulin acetylation changes downstream of MAG or CSPGs treatment (Figs. 3, 4), and that $\alpha \mathrm{TAT} 1$ reconstitution by lentiviral- $\alpha$ TAT1 infection can overcome neurite growth inhibition (Fig. 5C,D). These findings are also supported by the recent demonstration that overexpression of $\alpha$ TAT1 in DRG neurons significantly increases $\alpha$-tubulin acetylation toward the distal portion of the axon and significantly increases axon length (Lin et al., 2017). Furthermore, that $\alpha$-tubulin acetylation level is dependent on $\alpha$ TAT1 is consistent with a recent report demonstrating that $\alpha \mathrm{TAT} 1$ is highly expressed in mouse brain tissue, and that $\alpha \mathrm{TAT} 1$ deletion results in a near absence of acetylated $\alpha$-tubulin (Kim et al., 2013).

Our study, herein, also gives insight into how $\alpha$ TAT1 is regulated downstream of MAG and CSPGs signaling as a reduction in $\alpha \mathrm{TAT} 1$, and consequently $\alpha$-tubulin acetylation, can be prevented by inhibiting the RhoA-ROCK pathway (Figs. 2-4). Several studies have identified that MAG and CSPGs exert their axon growth inhibitory effects via a 
A
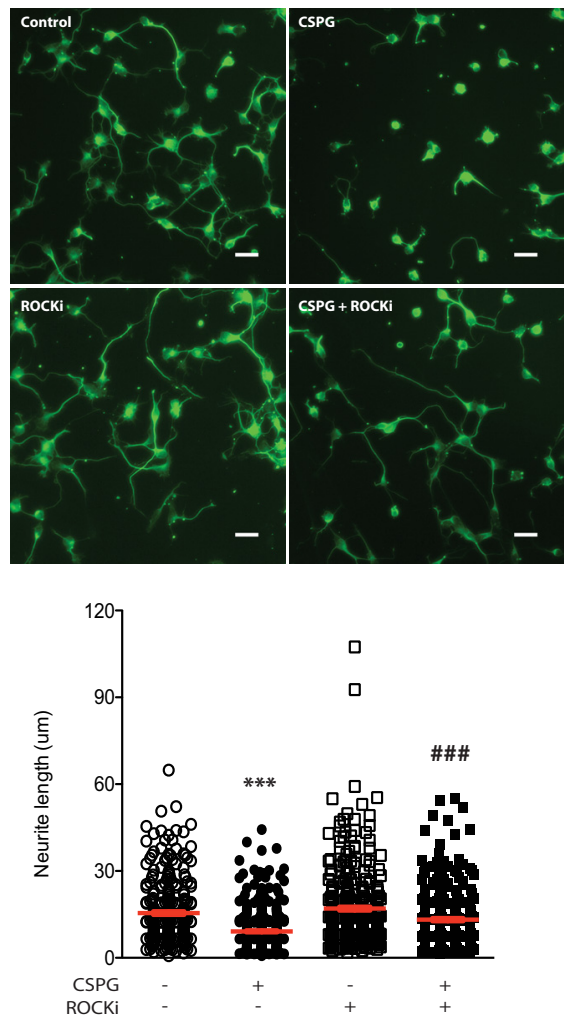

C
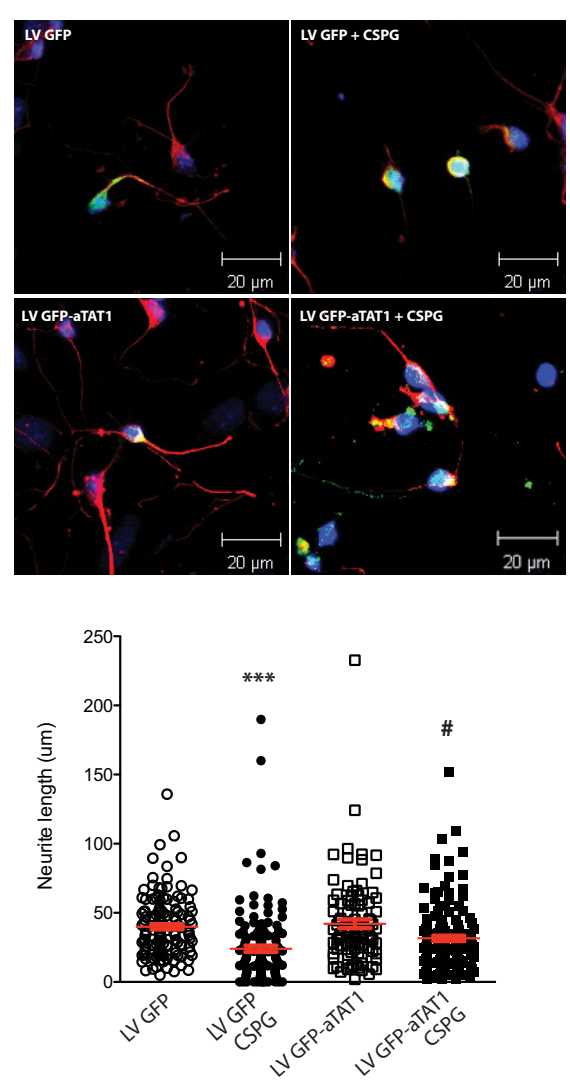
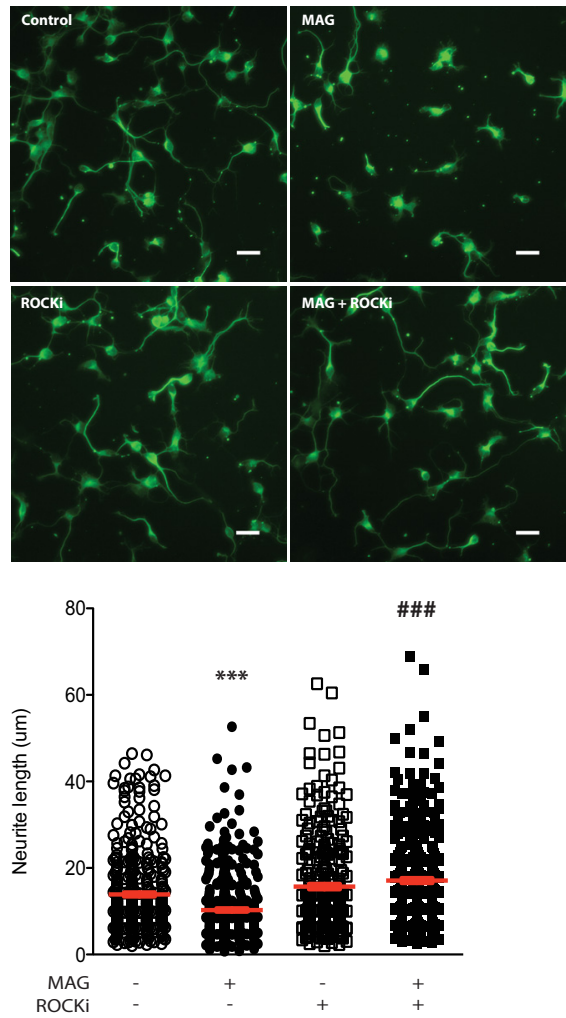

D
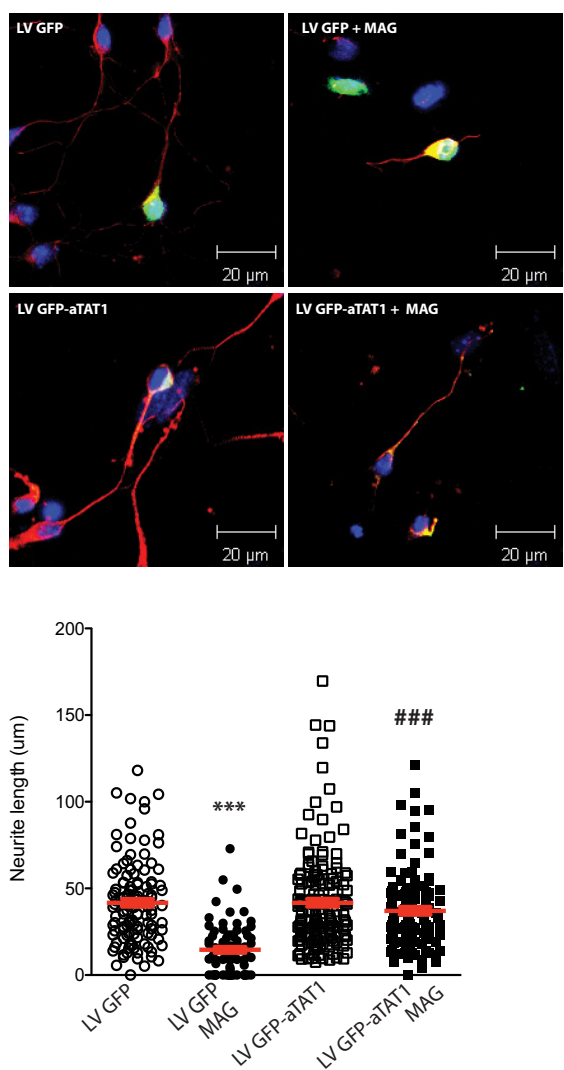

Figure 5. ROCK inhibition and overexpression of $\alpha \mathrm{TAT} 1$ reverse CSPGs- and MAG-induced inhibition of neurite outgrowth. $\boldsymbol{A}, \boldsymbol{B}$, Fluorescent microscopy of primary cortical neurons incubated with CSPGs $(2 \mu \mathrm{g} / \mathrm{ml} ; \boldsymbol{A})$ or MAG $(30 \mu \mathrm{g} / \mathrm{ml} ; \boldsymbol{B})$, with or without ROCK 
continued

inhibitor $(\mathrm{Y}-27632 ; 10 \mu \mathrm{M})$ for $24 \mathrm{~h}$. Neurite lengths and mean neurite length for each condition are shown in column scatter plots below micrographs. ***, CSPGs or MAG treatment versus untreated control $p<0.001$; \#\#\#, cotreatment with ROCKi versus treatment alone $p<0.001$ (one-way ANOVA followed by Bonferroni's post hoc test was performed). Scale bar, $10 \mu \mathrm{m}(\boldsymbol{A}, \boldsymbol{B})$. $\boldsymbol{C}, \boldsymbol{D}$, Confocal immunofluorescent microscopy of primary cortical neurons following infection with lentiviral GFP (LV GFP; control) or lentiviral GFP- $\alpha$ TAT1 (LV GFP- $\alpha$ TAT1) with or without CSPGs $(2 \mu \mathrm{g} / \mathrm{ml} ; \boldsymbol{C})$ or MAG $(30 \mu \mathrm{g} / \mathrm{ml}$; $\boldsymbol{D})$. Transduced neurites were identified by immunolabeling with antibodies for neuron-specific Tuj1 (1:5000; red) and GFP (1:500; green) and quantified with ImageJ software. Neurite lengths and mean neurite length for each condition are shown in column scatter plots below micrographs. ***, CSPGs or MAG treatment versus untreated control $p<0.001$; \# and \#\#\#, LV GFP- $\alpha$ TAT1 with CSPGs or MAG versus LV GFP with CSPGs or MAG, $p<$ 0.05 and $p<0.001$, respectively (two-way ANOVA followed by Bonferroni's post hoc test was performed). Scale bar, $20 \mu \mathrm{m}(\boldsymbol{C}, \boldsymbol{D})$.

receptor complex comprising Nogo receptor family members and p75NTR low-affinity neurotrophin receptors that in turn signal via the receptor-bound GTPase, RhoA. A wellcharacterized canonical downstream effector of RhoA is Rho-associated protein kinase, ROCK, which is involved in many aspects of neuronal functions including neurite outgrowth and retraction. As such, the axon growth-inhibitory effects of MAG and CSPGs can be reversed by blockade of the Rho-ROCK pathway in vitro and in vivo (Borisoff et al., 2003; Mimura et al., 2006; Hur et al., 2011).

The relationship between ROCK and acetylation of $\alpha$-tubulin has been underscored by studies in mice overexpressing $\alpha$ TAT1 that is deficient of catalytic activity but not $\alpha$-tubulin binding. These mutant animals have less
A
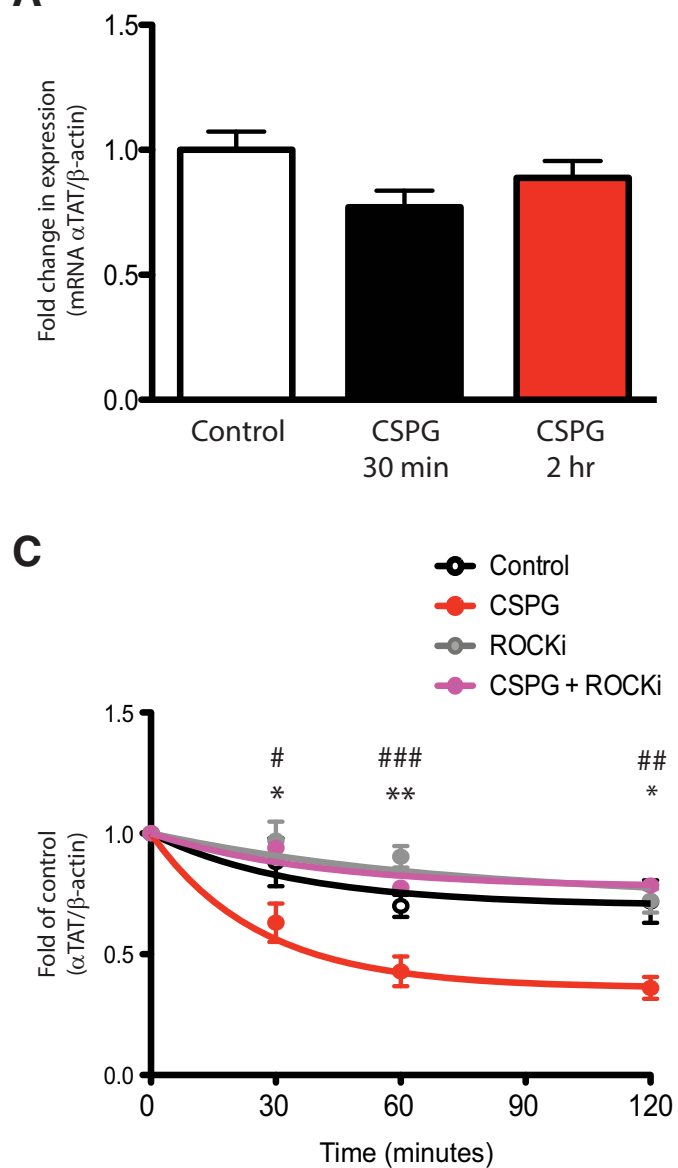

B
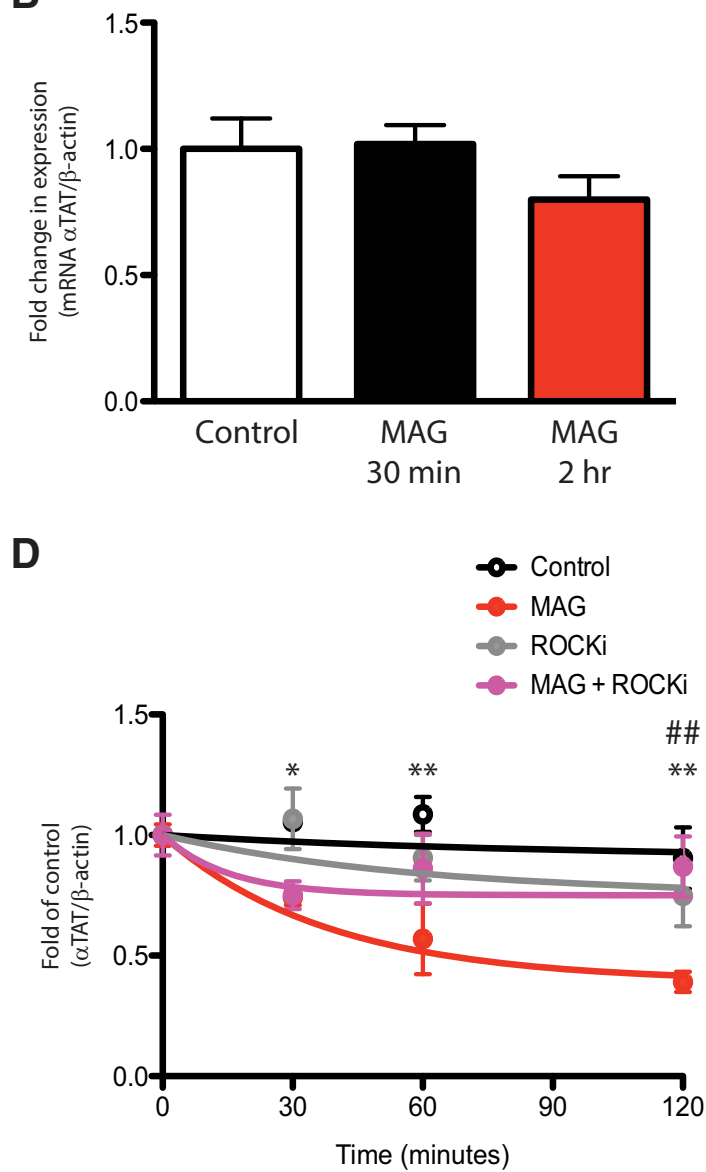

Figure 6. $\alpha$ TAT1 protein stability is reduced in cortical neurons treated with CSPGs or MAG. $\boldsymbol{A}, \boldsymbol{B}$, Bar graphs showing real-time quantitative RT-PCR results from primary cortical neurons incubated with CSPGs $(2 \mu \mathrm{g} / \mathrm{ml} ; \boldsymbol{A})$ or MAG $(30 \mu \mathrm{g} / \mathrm{ml} ; \boldsymbol{B})$ for $30 \mathrm{~min}$ or 2 h reveal no change in $\alpha T A T 1$ mRNA. $\boldsymbol{C}, \boldsymbol{D}$, Cycloheximide chase assay graphs showing $\alpha$ TAT1 protein degradation in primary cortical neurons over time after protein translation inhibition with cycloheximide $(10 \mu \mathrm{g} / \mathrm{ml})$. Neurons were treated with or without CSPGs $(2$ $\mu \mathrm{g} / \mathrm{ml} ; \boldsymbol{C})$ or MAG $(30 \mu \mathrm{g} / \mathrm{ml} ; \boldsymbol{D})$ and cotreated with or without ROCK inhibitor $(\mathrm{Y}-27632 ; 10 \mu \mathrm{M})$. *, Treatment with growth inhibitory substrate versus 0 min $p<0.05$; **, treatment with growth inhibitory substrate versus 0 min, $p<0.01$; \#, CSPGs or MAG cotreatment with ROCKi versus CSPGs or MAG treatment alone at 30 min, $p<0.05$; \#\#\#, CSPGs or MAG cotreatment with ROCKi versus CSPGs or MAG treatment alone at 60 min, $p<0.001$; \#\#, CSPGs or MAG treatment with ROCKi versus CSPGs or MAG treatment alone at $120 \mathrm{~min}, p<0.01$ (two-way ANOVA followed by Bonferroni's post hoc test was performed). 
acetylated $\alpha$-tubulin and enhanced microtubule depolymerization sensitivity to nocodazole (Kalebic et al., 2013a,b), a well-established activator of RhoA-ROCK pathway (Krendel et al., 2002; Chang et al., 2008). Here, we also reveal that activation of the RhoA-ROCK pathway by CSPGs and MAG act to decrease $\alpha$ TAT1 levels by decreasing its stability at a posttranslational level (Fig. 6). How RhoA-ROCK pathway regulates $\alpha$ TAT1 protein levels is still an open question. Previous studies established that RhoA has protein degradation effects, in particular, on p27 $7^{\mathrm{kip}}$ through regulation of cyclin E/CDK2 activity (Hirai et al., 1997; Hu et al., 1999). Expression of dominant-negative RhoA inhibited p27 $7^{\text {kip }}$ degradation in vitro (Hu et al., 1999). In addition to the traditional roles of RhoA on actin dynamics, our study and others strongly suggests that RhoA has a role in regulating protein degradation. While the mechanism behind RhoA signaling and $\alpha \mathrm{TAT} 1$ degradation remains elusive, this finding nevertheless places emphasis on the importance of events downstream of the RhoROCK pathway and identifying the stabilization/ destabilization domain(s) of $\alpha \mathrm{TAT} 1$ for drug development targets in promoting CNS axon regeneration in the presence of growth impeding factors such as CSPGs and MAG.

A critical question that remains is whether or not $\alpha$-tubulin acetylation is required for neurite growth. In neurons, microtubule arrays are constantly adapted to fit their physiologic needs by modulating the balance between dynamic shortlived, and stable long-lived microtubule sub-populations. During neurite extension, the more stable microtubules are needed in the proximal axon to drive forward growth, but those in the axon tip/growth cone must be highly dynamic if it is to grow and respond to extracellular stimuli (Tahirovic and Bradke, 2009; Bradke et al., 2012). Microtubule structure, organization, stability, and function are highly regulated by microtubule-associated proteins (MAPs) and posttranslational modifications. Spatial localizations of acetylated $\alpha$-tubulin along axons reflects differences in their stability, with enriched acetylation in the more long-lived or stabilized microtubule populations that predominate in the proximal axon region and low-level acetylation at neurite tips (Black et al., 1989; Webster and Borisy, 1989; Brown et al., 1992; Baas et al., 1993). It may be that stabilizing microtubules enables the tip of the axon push through what would be negative growth signals in the injured nervous system. This hypothesis would be consistent with recent findings, where taxol has been shown to stabilize microtubules and augment regeneration of injured optic nerve (Sengottuvel et al., 2011; Sengottuvel and Fischer, 2011) and injured spinal cord axons (Hellal et al., 2011).

In addition to microtubules serving as architectural elements that shape the elongation of growing axons, and they are key components of the machinery that transports mitochondria and material required for axon growth from their sites of synthesis in the cell body into the axon (Yogev et al., 2016). Several studies have revealed that microtubule acetylation affects the affinity and progressivity of microtubule motors, playing a positive role in motor-based trafficking in axons (Reed et al., 2006; Dom- pierre et al., 2007; Hammond et al., 2010; Alper et al., 2014; Godena et al., 2014). Dompierre et al., proposed that the neurodegenerative Huntington disorder might involve a defect in tubulin acetylation, and that increasing tubulin acetylation can enhance the recruitment of the molecular motors dynein and kinesin-1 to microtubules to promote vesicular transport in differentiated neurons (Dompierre et al., 2007). Thus, the role of $\alpha$-tubulin acetylation by $\alpha$ TAT1 in neurite extension might be to facilitate growth-requiring cargo delivery.

It is important to consider that we cannot exclude the possibility that the roles of $\alpha$ TAT1 and HDAC6 in axon regeneration are independent of $\alpha$-tubulin and/or their acetyltransferase and deacetylase activities, respectively. A recent study by Lin et al. (2017) found that while $\alpha$ TAT1 overexpression in DRGs increases axonal $\alpha$-tubulin acetylation in cultured DRG neurons, the overexpression of a catalytically inactive mutant, $\alpha$ TAT1-D157N, does not. Yet both the catalytically active and inactive $\alpha \mathrm{TAT} 1 \mathrm{~s}$ significantly increased axonal lengths in vitro. Similarly, with regard to $\alpha$-tubulin acetylation and microtubule stability, findings by Kalebic et al. (2013b) revealed that it is the interaction of $\alpha$ TAT1 with microtubules, and not acetylation per se, that is the critical factor regulating microtubule stability. Nevertheless, our findings here demonstrate an exciting and novel role for $\alpha \mathrm{TAT} 1$ as a critical acute mediator of axon growth that is regulated downstream of CSPGs and MAG, and the RhoA/ROCK signaling cascade, which is a known molecular target to promote axon regeneration. In addition to this previously unidentified role, our work suggests that protecting $\alpha \mathrm{TAT} 1$ stability/ levels may provide an additional robust strategy to overcome axonal regeneration failure after CNS injury. Furthermore, the interplay between $\alpha$ TAT1 and HDAC6 in the context of $\alpha$-tubulin acetylation will be an interesting area of future exploration. One can surmise that when $\alpha$ TAT1 is downregulated at the axonal tips, HDAC6 may become the predominant enzyme and promotes $\alpha$-tubulin deacetylation. Studies are under way to explore the spatio-temporal relationship between these two opposing enzymes in regulating axonal growth, as are studies to define the role of $\alpha$ TAT1 in vivo, especially in animal models of traumatic brain injury and spinal cord injury.

\section{References}

Akella JS, Wloga D, Kim J, Starostina NG, Lyons-Abbott S, Morrissette NS, Dougan ST, Kipreos ET, Gaertig J (2010) MEC-17 is an alpha-tubulin acetyltransferase. Nature 467:218-222. CrossRef Medline

Alper JD, Decker F, Agana B, Howard J (2014) The motility of axonemal dynein is regulated by the tubulin code. Biophys $\mathrm{J}$ 107:2872-2880. Medline

Baas PW, Ahmad FJ, Pienkowski TP, Brown A, Black MM (1993) Sites of microtubule stabilization for the axon. J Neurosci 13:21772185. Medline

Black MM, Baas PW, Humphries S (1989) Dynamics of alpha-tubulin deacetylation in intact neurons. J Neurosci 9:358-368. Medline

Borisoff JF, Chan CC, Hiebert GW, Oschipok L, Robertson GS, Zamboni R, Steeves JD, Tetzlaff W (2003) Suppression of Rhokinase activity promotes axonal growth on inhibitory CNS substrates. Mol Cell Neurosci 22:405-416. Medline 
Bradke F, Fawcett JW, Spira ME (2012) Assembly of a new growth cone after axotomy: the precursor to axon regeneration. Nat Rev Neurosci 13:183-193. CrossRef Medline

Brown A, Slaughter T, Black MM (1992) Newly assembled microtubules are concentrated in the proximal and distal regions of growing axons. J Cell Biol 119:867-882. Medline

Chang YC, Nalbant P, Birkenfeld J, Chang ZF, Bokoch GM (2008) GEF-H1 couples nocodazole-induced microtubule disassembly to cell contractility via RhoA. Mol Biol Cell 19:2147-2153. CrossRef

Cueva JG, Hsin J, Huang KC, Goodman MB (2012) Posttranslational acetylation of $\alpha$-tubulin constrains protofilament number in native microtubules. Curr Biol 22:1066-1074. CrossRef Medline

d'Ydewalle G, Bouckaert D, Brunfaut E (2001) Age-related differences and complexity of ongoing activities in time- and eventbased prospective memory. Am J Psychol 114:411-423.

Dell'Anno MT, Strittmatter SM (2017) Rewiring the spinal cord: direct and indirect strategies. Neurosci Lett 652:25-34.

Dergham P, Ellezam B, Essagian C, Avedissian H, Lubell WD, McKerracher $L$ (2002) Rho signaling pathway targeted to promote spinal cord repair. J Neurosci 22:6570-6577. Medline Medline

Desai A, Mitchison TJ (1997) Microtubule polymerization dynamics. Annu Rev Cell Dev Biol 13:83-117. CrossRef Medline

Domeniconi M, Cao Z, Spencer T, Sivasankaran R, Wang K, Nikulina E, Kimura N, Cai H, Deng K, Gao Y, He Z, Filbin M (2002) Myelinassociated glycoprotein interacts with the Nogo66 receptor to inhibit neurite outgrowth. Neuron 35:283-290. Medline

Dompierre JP, Godin JD, Charrin BC, Cordelières FP, King SJ, Humbert S, Saudou F (2007) Histone deacetylase 6 inhibition compensates for the transport deficit in Huntington's disease by increasing tubulin acetylation. J Neurosci 27:3571-3583. CrossRef Medline

Fournier AE, GrandPre T, Strittmatter SM (2001) Identification of a receptor mediating Nogo-66 inhibition of axonal regeneration. Nature 409:341-346. CrossRef Medline

Fournier AE, Takizawa BT, Strittmatter SM (2003) Rho kinase inhibition enhances axonal regeneration in the injured CNS. J Neurosci 23:1416-1423. Medline

Gardiner J, Barton D, Marc J, Overall R (2007) Potential role of tubulin acetylation and microtubule-based protein trafficking in familial dysautonomia. Traffic 8:1145-1149. CrossRef Medline

Godena VK, Brookes-Hocking N, Moller A, Shaw G, Oswald M, Sancho RM, Miller CC, Whitworth AJ, De Vos KJ (2014) Increasing microtubule acetylation rescues axonal transport and locomotor deficits caused by LRRK2 Roc-COR domain mutations. Nat Commun 5:5245. CrossRef Medline

Hammond JW, Huang CF, Kaech S, Jacobson C, Banker G, Verhey KJ (2010) Posttranslational modifications of tubulin and the polarized transport of kinesin-1 in neurons. Mol Biol Cell 21:572-583. CrossRef Medline

Hellal F, Hurtado A, Ruschel J, Flynn KC, Laskowski CJ, Umlauf M, Kapitein LC, Strikis D, Lemmon V, Bixby J, Hoogenraad CC, Bradke $F$ (2011) Microtubule stabilization reduces scarring and causes axon regeneration after spinal cord injury. Science 331: 928-931. CrossRef Medline

Hempen B, Brion JP (1996) Reduction of acetylated alpha-tubulin immunoreactivity in neurofibrillary tangle-bearing neurons in Alzheimer's disease. J Neuropathol Exp Neurol 55:964-972. Medline

Hirai A, Nakamura S, Noguchi Y, Yasuda T, Kitagawa M, Tatsuno I, Oeda T, Tahara K, Terano T, Narumiya S, Kohn LD, Saito Y (1997) Geranylgeranylated rho small GTPase(s) are essential for the degradation of p27Kip1 and facilitate the progression from $\mathrm{G} 1$ to $\mathrm{S}$ phase in growth-stimulated rat FRTL-5 cells. J Biol Chem 272:1316. CrossRef

Hu W, Bellone CJ, Baldassare JJ (1999) RhoA stimulates p27(Kip) degradation through its regulation of cyclin E/CDK2 activity. J Biol Chem 274:3396-3401. Medline

Hur EM, Yang IH, Kim DH, Byun J, Saijilafu Xu WL, Nicovich PR, Cheong R, Levchenko A, Thakor N, Zhou FQ (2011) Engineering neuronal growth cones to promote axon regeneration over inhibitory molecules. Proc Natl Acad Sci USA 108:5057-5062.
Janke C, Bulinski JC (2011) Post-translational regulation of the microtubule cytoskeleton: mechanisms and functions. Nat Rev Mol Cell Biol 12:773-786. CrossRef Medline

Jones LL, Margolis RU, Tuszynski MH (2003) The chondroitin sulfate proteoglycans neurocan, brevican, phosphacan, and versican are differentially regulated following spinal cord injury. Exp Neurol 182:399-411. Medline

Kalebic N, Sorrentino S, Perlas E, Bolasco G, Martinez C, Heppenstall PA (2013a) $\alpha$ TAT1 is the major $\alpha$-tubulin acetyltransferase in mice. Nat Commun 4:1962. CrossRef Medline

Kalebic N, Martinez C, Perlas E, Hublitz P, Bilbao-Cortes D, Fiedorczuk K, Andolfo A, Heppenstall PA (2013b) Tubulin acetyltransferase alphaTAT1 destabilizes microtubules independently of its acetylation activity. Mol Cell Biol 33:1114-1123.

Kim GW, Li L, Gorbani M, You L, Yang XJ (2013) Mice lacking $\alpha$-tubulin acetyltransferase 1 are viable but display $\alpha$-tubulin acetylation deficiency and dentate gyrus distortion. J Biol Chem 288: 20334-20350. CrossRef Medline

Krendel M, Zenke FT, Bokoch GM (2002) Nucleotide exchange factor GEF-H1 mediates cross-talk between microtubules and the actin cytoskeleton. Nat Cell Biol 4:294-301. CrossRef Medline

Langley B, D'Annibale MA, Suh K, Ayoub I, Tolhurst A, Bastan B, Yang L, Ko B, Fisher M, Cho S, Beal MF, Ratan RR (2008) Pulse inhibition of histone deacetylases induces complete resistance to oxidative death in cortical neurons without toxicity and reveals a role for cytoplasmic p21(waf1/cip1) in cell cycle-independent neuroprotection. J Neurosci 28:163-176. CrossRef Medline

Li M, Husic N, Lin Y, Christensen H, Malik I, Mclver S, LaPash Daniels CM, Harris DA, Kotzbauer PT, Goldberg MP, Snider BJ (2010) Optimal promoter usage for lentiviral vector-mediated transduction of cultured central nervous system cells. J Neurosci Methods 189:56-64. CrossRef

Lin S, Sterling NA, Junker IP, Helm CT, Smith GM (2017) Effects of $\alpha$ TAT1 and HDAC5 on axonal regeneration in adult neurons. PLoS One 12:e0177496. CrossRef Medline

Liu BP, Fournier A, GrandPré T, Strittmatter SM (2002) Myelinassociated glycoprotein as a functional ligand for the Nogo-66 receptor. Science 297:1190-1193. CrossRef Medline

McKeon RJ, Jurynec MJ, Buck CR (1999) The chondroitin sulfate proteoglycans neurocan and phosphacan are expressed by reactive astrocytes in the chronic CNS glial scar. J Neurosci 19:1077810788.

McKerracher L, David S, Jackson DL, Kottis V, Dunn RJ, Braun PE (1994) Identification of myelin-associated glycoprotein as a major myelin-derived inhibitor of neurite growth. Neuron 13:805-811. Medline

Mimura F, Yamagishi S, Arimura N, Fujitani M, Kubo T, Kaibuchi K, Yamashita T (2006) Myelin-associated glycoprotein inhibits microtubule assembly by a Rho-kinase-dependent mechanism. J Biol Chem 281:15970-15979. CrossRef Medline

Monnier PP, Sierra A, Schwab JM, Henke-Fahle S, Mueller BK (2003) The Rho/ROCK pathway mediates neurite growth-inhibitory activity associated with the chondroitin sulfate proteoglycans of the CNS glial scar. Mol Cell Neurosci 22:319-330. Medline

Mukhopadhyay G, Doherty P, Walsh FS, Crocker PR, Filbin MT (1994) A novel role for myelin-associated glycoprotein as an inhibitor of axonal regeneration. Neuron 13:757-767. Medline

Neumann B, Hilliard MA (2014) Loss of MEC-17 leads to microtubule instability and axonal degeneration. Cell Rep 6:93-103. CrossRef Medline

Nogales E, Wolf SG, Downing KH (1998) Structure of the alpha beta tubulin dimer by electron crystallography. Nature 391:199-203. CrossRef Medline

Reed NA, Cai D, Blasius TL, Jih GT, Meyhofer E, Gaertig J, Verhey KJ (2006) Microtubule acetylation promotes kinesin-1 binding and transport. Curr Biol 16:2166-2172. CrossRef Medline

Rivieccio MA, Brochier C, Willis DE, Walker BA, D'Annibale MA, McLaughlin K, Siddiq A, Kozikowski AP, Jaffrey SR, Twiss JL, Ratan RR, Langley B (2009) HDAC6 is a target for protection and 
regeneration following injury in the nervous system. Proc Natl Acad Sci USA 106:19599-19604. CrossRef Medline

Sengottuvel V, Fischer D (2011) Facilitating axon regeneration in the injured CNS by microtubules stabilization. Commun Integr Biol 4:391-393. CrossRef Medline

Sengottuvel V, Leibinger M, Pfreimer M, Andreadaki A, Fischer D (2011) Taxol facilitates axon regeneration in the mature CNS. J Neurosci 31:2688-2699. CrossRef Medline

Shen Y, Tenney AP, Busch SA, Horn KP, Cuascut FX, Liu K, He Z, Silver J, Flanagan JG (2009) PTPsigma is a receptor for chondroitin sulfate proteoglycan, an inhibitor of neural regeneration. Science 326:592-596. CrossRef Medline

Shida T, Cueva JG, Xu Z, Goodman MB, Nachury MV (2010) The major alpha-tubulin K40 acetyltransferase alphaTAT1 promotes rapid ciliogenesis and efficient mechanosensation. Proc Natl Acad Sci USA 107:21517-21522. CrossRef Medline

Tahirovic S, Bradke F (2009) Neuronal polarity. Cold Spring Harb Perspect Biol 1:a001644. CrossRef Medline

Tang X, Davies JE, Davies SJ (2003) Changes in distribution, cell associations, and protein expression levels of NG2, neurocan, phosphacan, brevican, versican V2, and tenascin-C during acute to chronic maturation of spinal cord scar tissue. J Neurosci Res 71:427-444. CrossRef Medline

Topalidou I, Keller C, Kalebic N, Nguyen KC, Somhegyi H, Politi KA, Heppenstall P, Hall DH, Chalfie M (2012) Genetically separable functions of the MEC-17 tubulin acetyltransferase affect microtubule organization. Curr Biol 22:1057-1065. CrossRef Medline

Wang KC, Kim JA, Sivasankaran R, Segal R, He Z (2002a) P75 interacts with the Nogo receptor as a co-receptor for Nogo, MAG and OMgp. Nature 420:74-78.
Wang KC, Koprivica V, Kim JA, Sivasankaran R, Guo Y, Neve RL, He $Z$ (2002b) Oligodendrocyte-myelin glycoprotein is a Nogo receptor ligand that inhibits neurite outgrowth. Nature 417:941-944.

Webster DR, Borisy GG (1989) Microtubules are acetylated in domains that turn over slowly. J Cell Sci 92:57-65.

Westermann S, Weber K (2003) Post-translational modifications regulate microtubule function. Nat Rev Mol Cell Biol 4:938-947. CrossRef Medline

Wong ST, Henley JR, Kanning KC, Huang KH, Bothwell M, Poo MM (2002) A p75(NTR) and Nogo receptor complex mediates repulsive signaling by myelin-associated glycoprotein. Nat Neurosci 5:1302-1308. CrossRef Medline

Yamashita T, Higuchi H, Tohyama M (2002) The p75 receptor transduces the signal from myelin-associated glycoprotein to Rho. J Cell Biol 157:565-570. CrossRef

Yiu G, He Z (2006) Glial inhibition of CNS axon regeneration. Nat Rev Neurosci 7:617-627. CrossRef Medline

Yogev S, Cooper R, Fetter R, Horowitz M, Shen K (2016) Microtubule organization determines axonal transport dynamics. Neuron 92: 449-460. CrossRef Medline

Zhang Y, Li N, Caron C, Matthias G, Hess D, Khochbin S, Matthias P (2003) HDAC-6 interacts with and deacetylates tubulin and microtubules in vivo. EMBO J 22:1168-1179. CrossRef Medline

Zhang $\mathrm{Y}$, Kwon S, Yamaguchi T, Cubizolles F, Rousseaux S, Kneissel M, Cao C, Li N, Cheng HL, Chua K, Lombard D, Mizeracki A, Matthias G, Alt FW, Khochbin S, Matthias P (2008) Mice lacking histone deacetylase 6 have hyperacetylated tubulin but are viable and develop normally. Mol Cell Biol 28:1688-1701. CrossRef Medline 